\title{
KAJIAN FRAKSI METANOL DARI EKSTRAK METILEN DIKLORIDA KULIT KAYU BATANG PELAWAN (Tristania whitiana Griff.) SEBAGAI ANTIBAKTERI
}

\author{
Purwantiningsih Sugita \\ Departemen Kimia FMIPA IPB Bogor \\ Email: atiek@indo.net.id
}

\begin{abstract}
Antibacterial compound from methanol fraction of methylene dichloride extract of pelawan bark had been studied. Pelawan bark was extracted using ethanol $95 \%$ and $\mathrm{CH}_{2} \mathrm{Cl}_{2}$-water (1:1), respectively. Extract of $\mathrm{CH}_{2} \mathrm{Cl}_{2}$ was partitioned using hexanemethanol $90 \%$ (1:1). Afterwards, methanol fraction was analyzed by thin layer chromatography methods to find the best eluent for column chromatography. The best eluent came from mixture of acetone-chloroform-methanol $(0,6: 4: 0,4)$. The fractionation yielded 16 fractions with the first $\left(\mathrm{M}_{1}\right)$ and the third $\left(\mathrm{M}_{5}\right)$ fractions became the one spotted fractions. $\mathrm{M}_{1}$ and $\mathrm{M}_{5}$ fractions were examined for their antibacterial activity using paper diffusion methods by determining minimum inhibitory concentration value. $\mathbf{M}_{1}$ fraction showed greater activity than $\mathrm{M}_{5}$ fraction with minimum inhibitory concentration value of $2,7857 \mathrm{mg} / \mathrm{mL}$. The result of phytochemistry test showed that both fractions contain terpenoid.
\end{abstract}

Keywords : pelawan, antibakteri

\section{PENDAHULUAN}

Pada saat sekarang ini penyakit yang disebabkan oleh mikroba makin meningkat sehingga memerlukan perhatian khusus mengingat adanya peningkatan prevalensi penyakit tersebut di negara-negara berkembang seperti Indonesia. Obat-obat antibiotik yang beredar cenderung merupakan senyawa sintetik yang menimbulkan efek samping sehingga kebutuhan obat-obatan berasal tumbuhan dari waktu ke waktu semakin besar dan kecenderungan back to nature mendorong para peneliti untuk mendapatkan senyawa tersebut terus menerus dilakukan.

Salah satu kekayaan tumbuhan hutan Indonesia yang belum banyak digali potensinya adalah Tristania whitiana atau yang lebih dikenal dengan nama daerah yaitu pelawan. Penelitianpenelitian terhadap tumbuhan pelawan sebagai tanaman obat sampai saat ini masih belum banyak dikaji sehingga membuka peluang untuk penelitian lebih lanjut. Spesies pohon ini termasuk famili Mirtaceae. Spesies ini kaya akan minyak atsiri yang telah digunakan masyarakat sebagai obat tradisional, yaitu sebagai antibakteri, antioksidan dan antifungi (antijamur). Keberadaan minyak atsiri dapat meningkatkan pengaturan aktivitas mikroba. Kestabilan antimikroba di dalam saluran pencernaan dapat menurunkan kasus diare dan penyakit pencernaan lain (Ulfah 2002). Untuk menangkap peluang ini pengetahuan khasiat kulit kayu tanaman pelawan lebih mendalam perlu dikaji lebih lanjut.

Utama et al. (2002) telah melakukan penapisan komponen bioaktif serbuk kulit kayu pelawan menggunakan pelarut heksana, metilen diklorida dan etilasetat secara berturut-turut. Ekstrak teraktif sebagai anti-bakteri terhadap bakteri Escherichia coli (ATCC 6538) adalah ekstrak etilasetat (EA), sedangkan ekstrak teraktif terhadap bakteri Staphylococcus aureus (ATCC 25922) adalah ekstrak metilendiklorida. Uji 
fitokimia tanaman ini mengandung senyawa flavonoid, terpenoid, tanin, dan saponin. Sugita et al. (2004) melaporkan bahwa fraksinasi EA dengan metode kromatografi kolom menghasilkan 5 fraksi dan salah satu fraksi yang paling aktif sebagai antibakteri yaitu fraksi D. Hasil uji kromatografi lapis tipis (KLT) silika gel, fraksi D memiliki Rf 0,81 pada campuran eluen etil asetat:kloroform:asam asetat $(2: 0,5: 0,5)$ dengan konsentrasi hambatan minimum (KHM) berturut-turut sebesar $2,5 \mu \mathrm{g} / \mathrm{mL}$ terhadap bakteri E. coli dan $2,9 \mu \mathrm{g} / \mathrm{mL}$ terhadap $S$. Aureus. Dari hasil uji fitokimia, fraksi D diduga merupakan senyawa dari kelompok flavonoid.

Potensi tanaman ini sebagai antibakteri sangat tinggi, oleh karena itu perlu dilakukan penelitian lebih lanjut untuk mengeksplorasi komponen bioaktif lainnya, khususnya komponen bioaktif yang terdapat dalam ekstrak metilen diklorida (EMM). Dari hasil penelitian Utama et al. (2002), uji fitokimia terhadap EMM menunjukkan adanya senyawa kelompok terpenoid. Pada penelitian ini akan dipelajari bagaimana pola penghambatan komponen bioaktif EMM terhadap dua mikroba uji yaitu $S$. aureus dan $E$. coli dengan metode difusi kertas. Pola penghambatan komponen bioaktif EMM juga akan dibandingkan dengan fraksi D dari ekstrak etil asetat yang telah diperoleh dari hasil penelitian sebelumnya.

\section{METODOLOGI PENELITIAN}

\section{Penyiapan dan Fraksinasi Ekstrak} Metanol (Ghisalberti (1993)

Serbuk pelawan sebanyak $1,3 \mathrm{~kg}$ diperkolasi dengan etanol 95\% selama 24 jam dan disaring. Ekstrak kasar etanol (ET) dipekatkan sampai kira-kira 1/10 volume awal, kemudian diasamkan dengan $\mathrm{H}_{2} \mathrm{SO}_{4} 2 \mathrm{M}$ hingga $\mathrm{pH}$ mencapai kisaran 3,5-4. ET diekstraksi dengan campuran metilen diklorida:air (1:1) sebanyak tiga kali. Lapisan metilen diklorida (EM) dan lapisan air-asam dipisahkan. EM dipekatkan, dan selanjutnya diekstraksi dengan campuran heksana:metanol 90\% (1:1) sebanyak tiga kali. Fraksi metanol dari ekstrak metilen diklorida (EMM) dipekatkan, kemudian difraksinasi menggunakan metode kromatografi kolom. Fraksinasi EMM dengan Kromatografi Kolom (KK) menggunakan fasa diam silika gel dengan fasa gerak bergradien dari pelarut kloroform-aseton-etil-asetat-metanol.

Sampel yang digunakan sebanyak 6.0392 g. Deteksi spot dilakukan dengan sinar UV pada panjang gelombang 254 atau $366 \mathrm{~nm}$ dan pewarna amonium fosfomolibdat dalam etanol (5\%). Fraksi hasil KK yang diuji aktivitas antibakterinya yaitu fraksi yang positif mengandung terpenoid. Metode pengujian aktivitas antibakteri yang digunakan yaitu metode difusi kertas. Bakteri uji yang digunakan yaitu $S$. aureus (NBRC 13267) dan E. coli (NBRC 14237). Fraksi aktif hasil KK dimurnikan lebih lanjut dengan KLT preparatif. Senyawa yang diperoleh diuji kemurniannya dengan KLT analitik. Senyawa murni dikarakterisasi dengan spektrofotometer UV-VIS dan FTIR.

\section{Uji Antibakteri}

Konsentrasi yang digunakan adalah $3,2 \mathrm{mg} / \mathrm{mL}, 6,3 \mathrm{mg} / \mathrm{mL}$, dan 12,5 $\mathrm{mg} / \mathrm{mL}$ dalam pelarut etil asetat. Tetrasiklin digunakan sebagai kontrol positif dan etil asetat sebagai kontrol negatif. Sebanyak $25 \mathrm{~mL}$ natural agar Oxoid CM 003 yang mengandung bakteri dituangkan kedalam cawan petri sampai ketebalan sekitar $4 \mathrm{~mm}$. Kertas difusi diletakkan di atas permukaan agar. Sebanyak $20 \mu$ l ekstrak aktif diisikan ke dalam kertas difusi dan cawan Petri ditutup rapat. Cawan Petri dimasukkan ke dalam referigerator $\left(10^{\circ} \mathrm{C}\right)$ selama 2 jam dan inkubasi pada suhu $37^{\circ} \mathrm{C}$ selama 24 jam. Zona penghambatan pertumbuhan bakteri diukur. Zona terlihat dengan adanya areal bening yang menunjukkan 
tidak adanya pertumbuhan bakteri uji. Hasil uji dinyatakan dalam diameter penghambatan (mm) yang perhitungannya tidak termasuk diameter kertas difusi.

\section{HASIL DAN PEMBAHASAN}

Eluen terbaik untuk fraksinasi EMM didapat dari campuran tiga pelarut yaitu aseton : kloroform : metanol $(0,6: 4,0: 0,4)$. Hasil kromatografi kolom EMM ditampilkan pada Tabel 1.
Berdasarkan jumlah rendemen yang diperoleh dari kromatografi kolom, dan jumLah spot fraksi pada uji pewarnaan dengan $\mathrm{H}_{2} \mathrm{SO}_{4}$ pekat sebagai uji terpenoid, sampel untuk uji antibakteri dipilih 2 fraksi yaitu fraksi $\mathrm{M}_{1}$ dan $\mathrm{M}_{5}$. Uji pewarnaan dengan $\mathrm{H}_{2} \mathrm{SO}_{4}$ pekat diperoleh jumLah spot baik fraksi $\mathrm{M}_{1}$ maupun $\mathrm{H}_{5}$ ialah satu spot dengan masing-masing Rf berturut-turut 0,79 dan 0,72 .

Tabel 1 Hasil fraksinasi EMM dengan kromatografi kolom

\begin{tabular}{|c|c|c|c|c|c|c|}
\hline Fraksi & $\begin{array}{c}\text { Bobot } \\
(\mathrm{g})\end{array}$ & $\begin{array}{c}\text { Rendemen* } \\
(\%)\end{array}$ & $\begin{array}{l}\text { Bentuk dan } \\
\text { warna }\end{array}$ & $\begin{array}{c}\text { Uji } \\
\text { terpenoid** }\end{array}$ & $\begin{array}{l}\text { JumLah } \\
\text { noda**** }\end{array}$ & $\mathrm{Rf} * * * *$ \\
\hline M1 & 0,3086 & 5,11 & Pasta, coklat & +++++ & 1 & 0,79 \\
\hline M2 & 0,2636 & 4,36 & Pasta, hijau & ++++ & $(\phi)$ & - \\
\hline M3 & 0,1306 & 2,16 & Serbuk, hijau & ++++ & $(\phi)$ & - \\
\hline M4 & 1,1547 & 19,12 & Pasta, coklat & ++++ & 2 & 0,$71 ; 0,81$ \\
\hline M5 & 0,1938 & 3,21 & $\begin{array}{l}\text { Oily, coklat } \\
\text { Pasta, }\end{array}$ & ++++ & 1 & 0,72 \\
\hline M6 & 0,2670 & 4,42 & $\begin{array}{l}\text { kuning, } \\
\text { kristal putih }\end{array}$ & - & 2 & 0,$53 ; 0,74$ \\
\hline M7 & 0,0157 & 0,26 & Pasta, coklat & ++++ & 5 & 0,$35 ; 0,56 ; 0,72$ \\
\hline M8 & 0,0247 & 0,41 & Pasta, coklat & ++++ & 5 & $\begin{array}{l}0,50 ; 0,52 ; 0,56 ; \\
0,71\end{array}$ \\
\hline M9 & 0,0453 & 0,75 & Pasta, coklat & ++++ & 4 & 0,$43 ; 0,70$ \\
\hline M10 & 0,0453 & 0,75 & Pasta, coklat & ++++ & 6 & $\begin{array}{l}0,37 ; 0,44 ; 0,58 \\
0,69 ; 0,73\end{array}$ \\
\hline M11 & 0,2047 & 3,39 & $\begin{array}{l}\text { Serbuk, } \\
\text { coklat }\end{array}$ & ++++ & 5 & $\begin{array}{l}0,35 ; 0,42 ; 0,69 ; \\
0,72\end{array}$ \\
\hline M12 & 0,0676 & 1,12 & Oily, coklat & ++ & 7 & $\begin{array}{l}0,36 ; 0,43 ; 0,49 \\
0,70\end{array}$ \\
\hline M13 & 0,1783 & 2,29 & Pasta, coklat & - & 4 & $\begin{array}{l}0,36 ; 0,42 ; 0,67 \\
0,72\end{array}$ \\
\hline M14 & 0,0132 & 0,22 & Pasta, coklat & - & - & - \\
\hline M15 & 0,0600 & 0,99 & Oily, coklat & +++ & 3 & 0,72 \\
\hline M16 & 0,0173 & 0,29 & Pasta, hijau & +++ & 3 & 0,$36 ; 0,67 ; 0,72$ \\
\hline
\end{tabular}

Keterangan:

* Rendemen terhadap EMM yang dikromatografi kolom

** Intensitas warna uji terpenoid

*** JumLah noda dari hasil uji pewarnaan dengan penambahan $\mathrm{H}_{2} \mathrm{SO}_{4}$ pekat pemanasan $80^{\circ} \mathrm{C}$. 15 menit

**** Nilai Rf yang diduga kelompok terpenoid

(ф) Tidak terjadi pemisahan

\section{Uji Aktivitas Antibakteri}

Aktivitas antibakteri dari fraksi $\mathrm{M}_{1}$ dan $\mathrm{M}_{5}$ dari EMM terhadap bakteri uji E.coli dan $S$. aureus disajikan pada Tabel 2. Penghambatan pertumbuhan kedua fraksi hanya terjadi terhadap E. coli. Fraksi $\mathrm{M}_{1}$ menunjukkan aktivitas antibakteri lebih besar dibandingkan fraksi $\mathrm{M}_{5}$ terhadap E. coli, sedangkan fraksi $M_{1}$ dan $M_{5}$ tidak menunjukkan adanya zona bening di sekitar kertas difusi terhadap bakteri $S$. aureus.

Tabel 2 juga memperlihatkan bahwa fraksi $\mathrm{M}_{1}$ memiliki aktivitas yang 
lebih tinggi dibandingkan dengan fraksi $\mathrm{M}_{5}$. Fraksi $\mathrm{M}_{1}$ telah menunjukkan adanya aktivitas antibakteri pada konsentrasi 3,20 $\mathrm{mg} / \mathrm{mL}$, sedangkan fraksi $\mathrm{M}_{5}$ baru menunjukkan aktivitas antibakteri pada konsentrasi $6,30 \mathrm{mg} / \mathrm{mL}$. Dari hasil uji statistik menyatakan bahwa hasil uji aktivitas antibakteri terhadap E. coli signifikan berbeda antara fraksi $\mathrm{M}_{1}$ dengan $\mathrm{M}_{5}$, hanya saja aktivitas fraksi $\mathrm{M}_{1}$ masih lebih rendah dari fraksi $\mathrm{D}$, fraksi teraktif dari ekstrak EA pada penelitian sebelumnya (Sugita et al. 2004). Fraksi D menghambat bakteri $E$. coli dan $S$. aureus. Pada konsentrasi $6,30 \mathrm{mg} / \mathrm{mL}$, fraksi D memberikan penghambatan sebesar 9,7 mm terhadap bakteri E. Coli, sedangkan fraksi $M_{1}$ hanya mampu menghambat sebesar 5,0 $\mathrm{mm}$. Dalam hal ini, fraksi $\mathrm{D}$ tidak dapat dilaporkan sebagai fraksi yang lebih aktif dari fraksi $\mathrm{M}_{1}$, karena hal ini terkait dengan parameter percobaan yang digunakan, seperti jenis metode difusi, galur bakteri, dan pelarut. Zona penghambatan fraksi $\mathrm{M}_{1}$ dan $\mathrm{M}_{5}$ terhadap E. coli disajikan pada Gambar 1.

Tabel 2. Hasil uji aktivitas antibakteri fraksi EMM hasil kromatografi kolom

\begin{tabular}{ccccc}
\hline $\mathrm{C}$ & \multicolumn{3}{c}{ E. coli } & \multicolumn{2}{c}{ S. aureus } \\
\cline { 2 - 5 }$(\mathrm{mg} / \mathrm{mL})$ & \multicolumn{3}{c}{ Diameter hambatan $(\mathrm{mm})$} \\
\cline { 2 - 5 } & $\mathrm{M}_{1}$ & $\mathrm{M}_{5}$ & $\mathrm{M}_{1}$ & $\mathrm{M}_{5}$ \\
\hline 3,20 & 1,0 & 0,0 & 0,0 & 0,0 \\
\hline 6,30 & 5,0 & 1,0 & 0,0 & 0,0 \\
\hline 12,50 & 6,0 & 1,0 & 0,0 & 0,0 \\
\hline
\end{tabular}

Gambar 1. menjelaskan bahwa makin tinggi konsentrasi maka makin besar daya hambat fraksi $\mathbf{M}_{1}$ dan $\mathbf{M}_{5}$. Etil asetat digunakan sebagai kontrol negatif tidak memiliki zona bening di sekitar kertas difusi. Penghambatan tetrasiklin sebagai kontrol positif terhadap bakteri $S$. aureus dan E. coli disajikan pada Tabel 3 dan Gambar 2.

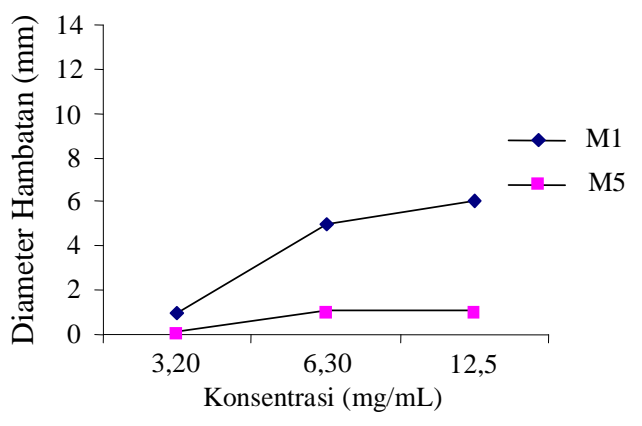

Gambar 1. Aktivitas antibakteri $\mathrm{M}_{1}$ dan $\mathrm{M}_{5}$ terhadap E. Coli

Variasi konsentrasi dilakukan untuk melihat kecenderungan daya hambat tetrasiklin terhadap dua golongan bakteri uji. Kedua bakteri dihambat pertumbuhannya dengan penggunaan tetrasiklin, sedangkan fraksi $\mathrm{M}_{1}$ hanya menghambat pertumbuhan bakteri $E$. coli. Diameter hambat tetrasiklin terhadap bakteri $E$. coli pada konsentrasi uji berkisar antara 14,0-24,0 $\mathrm{mm}$ sedangkan diameter hambat fraksi $\mathbf{M}_{1}$ berkisar antara 1,0-6,0 mm (Tabel 2.). Hasil penelitian Sugita et al. (2004), diameter hambat fraksi D berkisar 7,020,0 mm dan ampisilin sebagai kontrol positif menunjukkan diameter hambat pada kisaran 25-36 $\mathrm{mm}$. Diameter hambatan fraksi $\mathrm{M}_{1}$ terhadap E.coli pada konsentrasi $6,30 \mathrm{mg} / \mathrm{mL}$ menunjukkan aktivitas 3,3 kali lebih rendah dibandingkan tetrasiklin, dan sekitar 1,9 kali lebih rendah terhadap fraksi D. Mekanisme kerja tetrasiklin berbeda dengan ampisilin. Tetrasiklin menghambat sintesis protein sel bakteri, sedangkan ampisilin menghambat sintesis dinding sel bakteri (Jawetz et al. 1996). Baik fraksi $\mathrm{D}$ maupun $\mathrm{M}_{1}$ belum diketahui secara jelas mekanisme penghambatannya. 
Tabel 3. Daya hambatan tetrasiklin terhadap bakteri uji

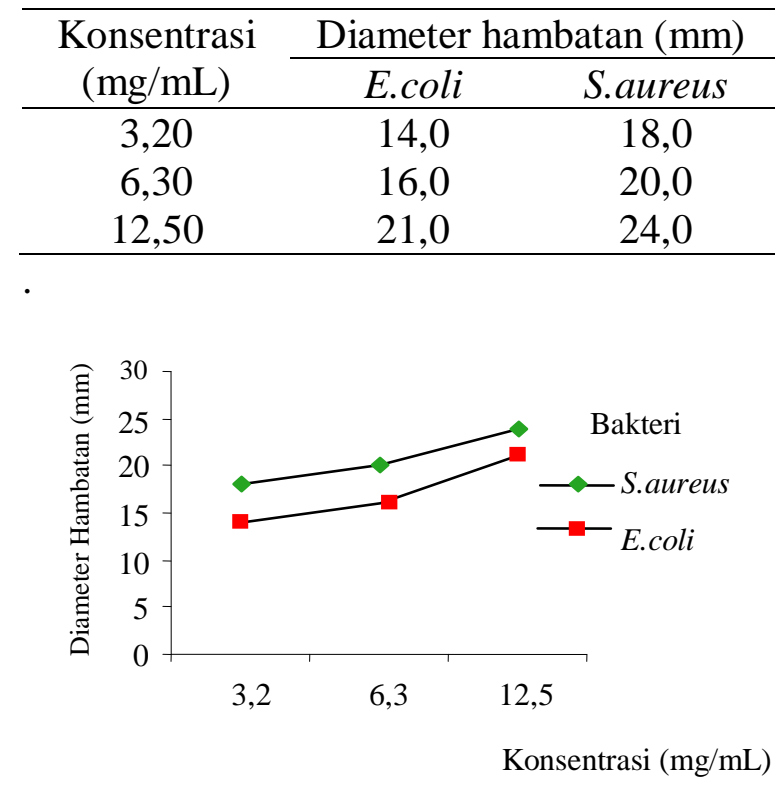

Gambar 2. Aktivitas antibakteri tetrasiklin terhadap E.coli dan S.aureus

Penentuan konsentrasi hambatan minimum (KHM) dihitung dengan menggunakan persamaan garis antara log konsentrasi fraksi (sumbu $x$ ) dengan diameter hambatan yang dihasilkan (sumbu y). Persamaan garis pada penentuan KHM fraksi $\mathbf{M}_{1}$ disajikan pada Gambar 3. Berdasarkan persamaan garis Gambar 3. nilai KHM fraksi $\mathbf{M}_{1}$ yaitu $2,7857 \mathrm{mg} / \mathrm{mL}$. Nilai KHM fraksi $\mathrm{M}_{1}$ lebih besar dari KHM fraksi D $(2,5$ $\mu \mathrm{g} / \mathrm{mL}$ ). Pada penelitian ini galur bakteri E.coli yang digunakan berbeda. Dari hasil uji statistik menyatakan bahwa aktivitas antibakteri fraksi $\mathbf{M}_{1}$ terhadap D untuk bakteri $E$. coli tidak signifikan berbeda.

Dari analisis fitokimia menggunakan pereaksi LiebermanBurchard (LB) dan $\mathrm{H}_{2} \mathrm{SO}_{4}$ pekat, fraksi $\mathrm{M}_{1}$ positif menunjukkan adanya senyawa golongan terpenoid. Pemurnian fraksi $\mathrm{M}_{1}$ dan identifikasi dengan UV dalam pelarut etil asetat menunjukkan panjang gelombang maksimum $\left(\lambda_{\text {maks }}\right)$ pada 313.0 $\mathrm{nm}$, sedangkan pengukuran IR menunjukkan adanya gugus $\mathrm{C}=\mathrm{O}$ aldehida, dan uluran $\mathrm{O}-\mathrm{H}$.

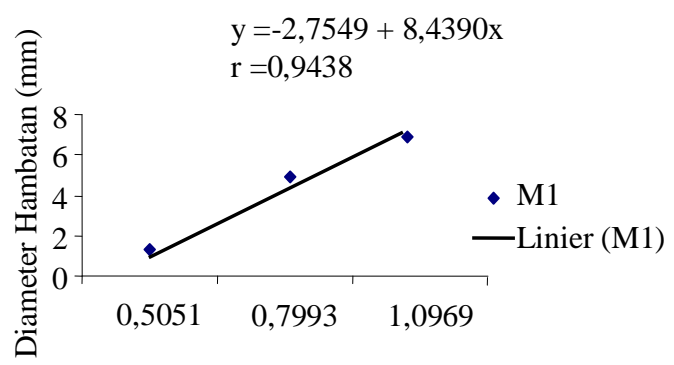

Log Konsentrasi

Gambar 3. Persamaan garis fraksi $\mathrm{M}_{1}$ untuk bakteri E.coli

\section{KESIMPULAN DAN SARAN Kesimpulan}

Fraksinasi EMM dengan gradien pelarut aseton-kloroform-metanol menghasilkan 16 fraksi. Dua diantaranya yaitu $\mathbf{M}_{1}$ dan $\mathrm{M}_{5}$ positif terhadap uji terpenoid. Kedua fraksi tidak menghambat pertumbuhan bakteri $S$. Aureus, sedangkan salah satu dari dua fraksi yaitu $\mathrm{M}_{1}$ menghambat pertumbuhan bakteri $E$. coli dengan nilai KHM $2,7857 \mathrm{mg} / \mathrm{mL}$. Senyawa bioaktif fraksi $M_{1}$ memiliki $\lambda_{\text {maks }}$ sebesar 313,0 $\mathrm{nm}$ dalam pelarut etil asetat, dan mengandung gugus $\mathrm{C}=\mathrm{O}$, aldehida \& $\mathrm{O}-\mathrm{H}$.

Saran

Perlu dilakukan pemurnian untuk mendapatkan komponen lebih murni yang dilanjutkan identifikasi dengan menggunakan NMR dan MS dan juga kajian tentang mekanisme penghambatan fraksi M1 terhadap E.coli.

\section{UCAPAN TERIMA KASIH}

Penelitian ini merupakan bagian dari penelitian payung dengan judul Potensi Pelawan (Tristania whitiana Griff.) sebagai Senyawa Anti Bakteri yang didanai dari dana Hibah Penelitian SP4 Departemen Kimia FMIPA IPB tahun anggaran 2004. Ucapan terima kasih diberikan kepada rekan peneliti, 
mahasiswa Sri Haryati Wahyuningsih dan Miftah Farid atas kerjasamanya yang baik.

\section{DAFTAR PUSTAKA}

Cowan, MM. 1999. Plant Product as Antimicrobial Agents. Clin Microbiol Rev 12: 564-582.

Ghisalberti EL. 1993. Detection and Isolation of Bioactive Natural Products. In Colegate SM and Molyneux RJ: Bioactive Natural Product. London. CRC Press. Hlm. 10-49.

Heyne K. 1987. Tumbuhan Berguna Indonesia Jilid ke-3. Terjemahan Balitbang Kehutanan, Jakarta.

Jawetz E. Melnick J.L. \& Adelberg E.A. 1996. Mikrobiologi Kedokteran. Ed. Ke 20. Terjemahan Nugroho E \& Maulany R.F. Penerbit Buku Kedokteran EGC, Jakarta

Jonathan S. G, Fasidi I. O. 2003. Antimicrobial Activities of Two Nigeria Edible Macrofungi Lycoperdon pusilum (Bat. ex) and Lycoperdon giganteum Pers). Afr J Biomed Res 6:85-90.

Nakamura C. V, T. U. Nakamura, E Bando, AFN Melo, DAG Cortez, and BPD Filho. 1999. Antibacterial Activity of Ocimum gratissimum L. Essential Oil. Mem Inst Oswaldo Cruz 94:675678.

Pandey B, P Ghimire1, and VP Agrawal. 2002. Studies on the antibacterial activity of the Actinomycetes isolated from the Khumbu Region of Nepal. http://www.aeh ms.org/pdf/panday\%20F.pdf [3 Jan 2005].
Sugita P., L. Sutedja dan E. P. Utama. 2004. Karakteristik Fraksi Aktif dari Ekstrak Etil Asetat Kulit Batang Pelawan (Tristania whitiana, Griff) yang Berpotensi sebagai Antibakteri, Simposium Nasional Kimia Bahan Alam XIV: Kimia Bahan Alam untuk Indonesia, Bandung 16-17 Desember 2004

Ulfah M. 2002. Minyak esensial alternatif pengganti antibiotika. http://www. kompas.com [26 Agustus 2002].

USDA Forest Service. 2002. Wood Technical Fact Sheet. http://www2.flp.fs.fed.us/TechSh eet/Chudnoff/SEAsian\&Oceania/ htmLDocs\%20seasian.Tristaniasp p.htmL [19 Mei 2004].

Utama EP., P. Sugita, dan L. Sutedja. 2002. Senyawa Antibakteri dari Ekstrak Etil Asetat Kulit Batang Pelawan (Tristania Whitiana Griff.) [skripsi]. Bogor: Fakultas Matematika dan Ilmu Pengetahuan Alam, Institut Pertanian Bogor. 